\title{
Quantitative trait locus mapping identifies Col4a6 as a novel regulator of striatal dopamine level and axonal branching in mice
}

\author{
Mélanie H. Thomas ${ }^{1 \#}$, Yujuan Gui ${ }^{2 \#}$, Pierre Garcia ${ }^{1,3,4}$, Mona Karout ${ }^{1}$, Christian \\ Jaeger $^{1}$, Zdenka Hodak ${ }^{1}$, Alessandro Michelucci ${ }^{1,5}$, Heike Kollmus ${ }^{6}$, Arthur Centeno ${ }^{7}$, \\ Klaus Schughart ${ }^{6,8,9}$, Rudi Balling ${ }^{1}$, Michel Mittelbronn ${ }^{1,3,4,5}$, Joseph H. Nadeau ${ }^{10,11}$, \\ Robert W. Williams ${ }^{7}$, Thomas Sauter ${ }^{2}$, Lasse Sinkkonen ${ }^{2 *}$, Manuel Buttini ${ }^{{ }^{*}}$ \\ ${ }^{1}$ Luxembourg Centre for Systems Biomedicine (LCSB), University of Luxembourg, Belvaux, Luxembourg \\ ${ }^{2}$ Department of Life Sciences and Medicine (DLSM), University of Luxembourg, Belvaux, Luxembourg \\ ${ }^{3}$ National Center of Pathology (NCP), Laboratoire National de Santé (LNS), Dudelange, Luxembourg \\ ${ }^{4}$ Luxembourg Centre of Neuropathology (LCNP), Luxembourg. \\ ${ }^{5}$ Neuro-Immunology Group, Department of Oncology (DONC), Luxembourg Institute of Health (LIH), \\ Luxembourg, Luxembourg \\ ${ }^{6}$ Department of Infection Genetics, Helmholtz Centre for Infection Research, Braunschweig, Germany \\ ${ }^{7}$ Department of Genetics, Genomics and Informatics, University of Tennessee Health Science Center, Memphis, \\ USA \\ ${ }^{8}$ University of Veterinary Medicine Hannover, Hannover, Germany \\ ${ }^{9}$ Department of Microbiology, Immunology and Biochemistry, University of Tennessee Health Science Center, \\ Memphis, Tennessee, USA \\ ${ }^{10}$ Pacific Northwest Research Institute, Seattle, Washington, United States \\ ${ }^{11}$ Maine Medical Center Research Institute, Scarborough, Maine USA \\ *Corresponding authors: Drs. Lasse Sinkkonen (lasse.sinkkonen@uni.lu), Manuel Buttini \\ (manuel.buttini@uni.lu) \\ \#These authors contributed equally
}

Key words: Col4a6 - mouse strains - dopamine - QTL - regulatory variants - nigrostriatal circuit 
Thomas et al:: Genetic Regulators of Nigrostriatal Circuit

\begin{abstract}
The features of dopaminergic neurons (DAns) of nigrostriatal circuitry are orchestrated by a multitude of yet unknown factors, many of them genetic. Genetic variation between individuals at baseline can lead to differential susceptibility to and severity of diseases. As decline of DAns, a characteristic of Parkinson's disease, heralds a significant decrease in dopamine level, measuring dopamine can reflect the integrity of DAns. To identify novel genetic regulators of the integrity of DAns, we used the Collaborative Cross (CC) mouse strains as model system to search for quantitative trait loci (QTLs) related to dopamine levels in the dorsal striatum. The dopamine levels in dorsal striatum varied greatly in the eight $\mathrm{CC}$ founder strains, and the differences were inheritable in 32 derived CC strains. QTL mapping in these CC strains identified a QTL associated with dopamine level on chromosome X containing 393 genes. RNA-seq analysis of the ventral midbrain of two of the founder strains with large striatal dopamine difference (C57BL/6J and A/J) revealed 24 differentially expressed genes within the QTL. The protein-coding gene with the highest expression difference was Col4a6, which exhibited a 9-fold reduction in A/J compared to C57BL/6J, consistent with decreased dopamine levels in A/J. Publicly available single cell RNA-seq data from developing human midbrain suggests that Col4a6 is highly expressed in radial glialike cells and neuronal progenitors, indicating possible involvement in neurogenesis. Interestingly, the lowered dopamine levels were accompanied by reduced striatal axonal branching of striatal DAns in A/J compared to C57BL/6J. Because Col4a6 is known to control axogenesis in non-mammal model organisms, we hypothesize that different dopamine levels in mouse dorsal striatum are due to differences in axogenesis induced by varying COL4A6 levels during neural development.
\end{abstract}


Thomas et al:: Genetic Regulators of Nigrostriatal Circuit

\section{Introduction}

Dopamine (DA), one of the main neurotransmitters in mammalian brain, is involved in several important activities such as motor and cognitive function. Using the amino acid tyrosine as a building block, dopaminergic neurons (DAns) can synthesize DA with two enzymes: tyrosine hydroxylase (TH) and DOPA-decarboxylase (Nagatsu et al., 2019). Two important populations of DAns, with distinct activities, locate in substantia nigra (SN) and ventral tegmental area (VTA) in the ventral midbrain. The DAns in SN project mainly to dorsal striatum and control motor function, while the ones in VTA project either to nucleus accumbens and amygdala, controlling reward and emotion, or to the cognitive centres in cortex and hippocampus, governing cognition and memory (Hassan and Benarroch, 2015; Vogt Weisenhorn et al., 2016). Both DAns are at the centre of neuroscience study because of their involvement in neurological diseases, notably VTA DAn in neuropsychiatric diseases and SN DAn in Parkinson's disease (PD).

Because of its prevalence and costs to society with an aging population, PD has received a lot of attention over the last decade. Studies brought to light the importance of environmental and genetic risk factors in the variability of PD (Del Rey et al., 2018; Gilgun-Sherki et al., 2004; van Rooden et al., 2011; Jankovic et al., 1990). The different age of onset, severity, and rate of progression of $\mathrm{PD}$ motor symptoms, as well as the variable response to dopamine replacement therapies are likely due to human genetic polymorphism (Kaplan et al., 2014; Kalinderi et al., 2011). Yet the underlying factors governing the outcome of these polymorphisms are mostly unknown. As genetic studies with standardized and controlled environment are difficult to handle in human, mouse models are commonly used to study genetic variations. Indeed, mouse shares similar brain architecture and $99 \%$ of genes with 
Thomas et al:: Genetic Regulators of Nigrostriatal Circuit

human and allows cost-effective and controlled studies (Nadeau and Auwerx, 2019).

Recombinant inbred mouse strains constitute interesting models to identify candidate genes with a method of quantitative trait locus (QTL) mapping (Peters et al., 2007). Collaborative Cross (CC) strains are a resource of recombinant inbred strains derived from eight founder strains for complex trait analysis, capturing an abundance of genetic diversity (Churchill et al., 2004). Genetic variation is also associated with phenotypic differences in the dopaminergic circuitry and the associated behaviours. Differences in the DAn cell number as well as in DA levels and protein trafficking have been shown between different strains of mice (Baker et al., 1980; Vadász et al., 1987; Vadasz et al., 1998; Zaborszky and Vadasz, 2001; Cabib et al., 2002). Motor behaviour and susceptibility to PD-toxin are also known to differ according to the mouse genetic background (Jong et al., 2010; Ingram et al., 1981; Brooks et al., 2004; Hamre et al., 1999). Altogether, previous works suggest that the dopaminergic circuitry is affected by genetic variation. But many factors underlying this variation are largely unknown.

In our study, we used CC mouse strains as a tool to map QTL related to the integrity of DAns. We measured dopamine level in the striata of eight $\mathrm{CC}$ founders and 32 derived $\mathrm{CC}$ strains, and observed that the striatal dopamine level was influenced by the genetic background of the strains. We identified a QTL associated with striatal dopamine level on chromosome $X$ that contained 393 genes. The transcriptomic analysis of C57BL/6J and A/J ventral midbrains, two CC founders having large striatal dopamine level differences, revealed 24 differentially expressed genes within the QTL, with Col4a6 showing the highest expression difference. Published studies using single cell RNA-seq data of developing human midbrain, have revealed a developmental expression profile for Col4a6 indicating a role in neurogenesis (La Manno et al., 2016), and morphological studies in non-mammal models (Drosophila and zebrafish) indicate a role in axon guidance and neurite outgrowth (Mirre et 
Thomas et al:: Genetic Regulators of Nigrostriatal Circuit

al., 1992; Takeuchi et al., 2015). Consistently, measurements of TH-positive axons in projection areas of SN DAns (dorsal striatum) and of VTA DAns (piriform cortex, amygdala) revealed that axonal branching of SN DAns, but not that of VTA DAns, differed between $\mathrm{C} 57 \mathrm{BL} / 6 \mathrm{~J}$ and $\mathrm{A} / \mathrm{J}$. However, the number of TH-positive neurons in the $\mathrm{SN}$ did not differ between these 2 strains. These observations indicate that differences in Col4a6 expression lead to differences in dopaminergic striatal innervation.

\section{Materials and methods}

\section{Animals}

Eight parental founder strains (A/J, C57BL/6J, 129S1Sv/ImJ, CAST/EiJ, PWK/PhJ, WSB/EiJ, NOD/ShiLtJ, NZO/H1LtJ) and 32 CC strains (Supplementary Table S1), originally obtained from the University of North Carolina, Chapel Hill (UNC), were bred at Chapel Hill or at the Central Animal Facilities of the Helmholtz Centre for Infection Research (Braunschweig, Germany). 10 to 12 mice per group (mixed males and females) were anesthetized with a ketamine-medetomidine $\operatorname{mix}(150$ and $1 \mathrm{mg} / \mathrm{kg}$, respectively). Intracardiac perfusion was performed (phosphate-buffered saline) for each animal before dissecting the striatum and midbrain, immediately snap-frozen. The second hemibrain was fixed in paraformaldehyde (PFA) 4\%. The experiments were performed according to the national guidelines of the animal welfare law in Germany (BGB1. I S. 1206, 1313 and BGB1. I S. 1934) and the European Communities Council Directive 2010/63/EU. The protocol was reviewed and approved by the 'Niedersächsisches Landesamt für Verbraucherschutz und Lebensmittelsicherheit, Oldenburg, Germany' (Permit Numbers: 33.9-42502-05-11A193, 33.19-42502-05-19A394), respecting the 3 Rs' requirements for Animal Welfare. 
Thomas et al:: Genetic Regulators of Nigrostriatal Circuit

\section{Dopamine measurements by gas chromatography-mass spectrometry (GC-MS)}

Striatal DA was measured in 3-month-old CC founders and $32 \mathrm{CC}$ strains. As we used two different methods to extract the metabolites from the tissues, we present the results as percentage of $\mathrm{C} 57 \mathrm{BL} / 6 \mathrm{~J}$. The tissue homogenization and metabolite extraction were performed at $4^{\circ} \mathrm{C}$ or lower to prevent changes in the metabolic profile.

The first method was described by Jaeger et al., 2015 (Jaeger et al., 2015). The striatum of each mouse was pulverized in a bead mill with grinding beads $(7 \mathrm{~mm})$. The samples were then homogenized in the bead mill with smaller grinding beads $(1 \mathrm{~mm})$ and the extraction fluid (methanol/distilled water, 40:8.5 v/v). The metabolites were extracted using a liquidliquid extraction method first by addition of chloroform to the tissue fluid followed by distilled water. After shaking for 20 minutes at $1300 \mathrm{rpm}$ at $4^{\circ} \mathrm{C}$, the mixture was centrifuged for 5 minutes at $5000 \mathrm{x} \mathrm{g}$ at $4^{\circ} \mathrm{C}$. The upper phase containing the polar metabolites was transferred to a sample vial for speed vacuum evaporation.

For both methods, the resulting dried samples were derivatized in an established procedure. $20 \mu \mathrm{L}$ of pyridine (containing $20 \mathrm{mg} / \mathrm{mL}$ of methoxyamine hydrochloride) were added to the samples and incubated at $45{ }^{\circ} \mathrm{C}$ with continuous shaking for $90 \mathrm{~min}$. Then $20 \mu \mathrm{L}$ of MSTFA were added to the sample vial and incubated $30 \mathrm{~min}$ at $45^{\circ} \mathrm{C}$ with continuous shaking.

After derivatization, the GC-MS analysis was performed with an Agilent 7890A GC, or 7890B for the second method, coupled to an Agilent 5975C inert XL mass selective detector (MSD) or 5977A for the second method (Diegem, Belgium). $1 \mu \mathrm{L}$ of sample was injected into a Split/Splitless inlet operating in split mode (10:1) at $270{ }^{\circ} \mathrm{C}$. Helium was used as a carrier gas with a constant flow rate of $1.2 \mathrm{~mL} / \mathrm{min}$. The second method was slightly modified to further reduce the runtime. The GC oven temperature was held 1 min at $80{ }^{\circ} \mathrm{C}$ 
Thomas et al:: Genetic Regulators of Nigrostriatal Circuit

(0.6 min at $90{ }^{\circ} \mathrm{C}$ for the second method) and increased at $36{ }^{\circ} \mathrm{C} / \mathrm{min}$ to $260{ }^{\circ} \mathrm{C}$ (at $25{ }^{\circ} \mathrm{C} / \mathrm{min}$ to $200{ }^{\circ} \mathrm{C}$ and held for 6 min for the second method). Then the temperature was increased at $22{ }^{\circ} \mathrm{C} / \mathrm{min}$ and maintained at a constant temperature of $325^{\circ} \mathrm{C}$ for $2 \min (4 \mathrm{~min}$ post run time at $325{ }^{\circ} \mathrm{C}$ for the second method). The transfer line temperature was set constantly to $280{ }^{\circ} \mathrm{C}$ and the MSD was operating under electron ionization at $70 \mathrm{eV}$. As described by Jäger et al., 2016 (Jäger et al., 2016), a multi-analyte detection using a quadrupole analyzer in selected ion monitoring mode was used for a sensitive and precise quantification of DA and the internal standard DA- $d 4$.

Statistical analysis was performed using the GraphPad Prism 8 software. After applying the Shapiro-Wilk test to assess the normality of our data, a one-way ANOVA was applied to analyse the striatal dopamine levels.

\section{Immunofluorescence}

TH protein was measured by immunofluorescence in the dorsal striatum, amygdala, piriform cortex, and SN of 3-month-old C57BL/6J and A/J. From 6 to 14 hemibrains per group were fixed (PFA 4\%) for $48 \mathrm{~h}$ and stored in PBS with $0.2 \%$ of sodium azide. Parasagittal free floating sections $(50 \mu \mathrm{m})$ were generated using a vibratome (Leica; VT 1000S) collected every $4^{\text {th }}$ sections in a tube containing a cryoprotective medium (polyvinyl pyrrolidone $1 \%$ w/v in PBS/ethylene glycol $1: 1)$ and stored at $-20^{\circ} \mathrm{C}$. The lateral sections were collected for the striatum, amygdala and piriform cortex measurements, and the medial sections were collected for the SN measurements.

The sections were washed in PBS with $0.1 \%$ Triton X-100 (PBST) and permeabilized in PBS with $3 \% \mathrm{H}_{2} \mathrm{O}_{2}$ and $1.5 \%$ Triton $\mathrm{X}-100$. The sections were then blocked for $1 \mathrm{~h}$ in PBST with 5\% of Bovine Serum Albumin (BSA) and incubated overnight with rabbit anti-TH antibody 
Thomas et al:: Genetic Regulators of Nigrostriatal Circuit

(1:1000, Millipore, AB152) diluted in PBST with 2\% of BSA. After several washing, the sections were incubated for 2 hours with the secondary antibody (Alexa fluor ${ }^{\mathrm{TM}} 488$ goat anti-rabbit 1:1000, Invitrogen), mounted on slides and embedded in fluoromount.

Imaging was performed using a Zeiss AxioImager Z1 upright microscope, coupled to a "Colibri” LED system, and an Mrm3 digital camera for image capture using the software Zeiss Zen 2 Blue. For each striatum, amygdala and piriform cortex section, three images of each brain area were taken at 40x magnification using the apotome system. After thresholding, the area occupied by TH stainings in each picture was determined using the FIJI imaging software (Schindelin et al., 2012; Masliah et al., 2000). For the SN sections, the pictures were taken at 10x magnification. The area occupied by $\mathrm{TH}$ positive neurons was measured in the region of interest corresponding to the SN using ImageJ FIJI software. We can distinguish four different areas of the SN. Each area was quantified and averaged separately and summed as a cumulated surface $\left(\mathrm{mm}^{2}\right)$ (Ashrafi et al., 2017).

GraphPad Prism 8 software was used for the statistical analysis. After applying the ShapiroWilk test to assess the normality of our data, an unpaired t-test was applied to analyse the TH measurement in different areas.

\section{Quantitative trait locus mapping}

The QTL mapping was done with http://gn2.genenetwork.org/. The dataset containing dopamine measurements of dorsal striata of $32 \mathrm{CC}$ strains were located with search terms (Species: Mouse (mm10); Group: CC Family; Type: Phenotypes; Dataset: CC Phenotypes) and navigated to Record CCF_10001 and CCF_10002. The QTL mapping was done with GEMMA on all chromosomes, MAF > $=0.05$ with LOCO method. The genome wide 
Thomas et al:: Genetic Regulators of Nigrostriatal Circuit

significance of QTL mapping on male and female are set by 500 permutation simulations with FDR under 5\% for each scan.

\section{Estimation of ventral dopamine level heritability in CC strains}

The broad sense heritability is estimated based on (Belknap, 1998). Briefly, the total phenotypic variance $(\mathrm{Vp})$ is calculated on all $\mathrm{CC}$ strains. The genetic variance (Va) is estimated by the mean of within-strain variance. The heritability $\left(\mathrm{H}^{2}\right)$ is calculated as $\mathrm{Va} / \mathrm{Vp}$.

\section{Results}

\section{Differences in striatal dopamine levels across Collaborative Cross mice are under genetic control}

To determine whether the reported phenotypic differences between $\mathrm{CC}$ mouse strains (Schoenrock et al., 2018; Schoenrock et al., 2020) are accompanied by differences in striatal DA levels, we measured DA levels in isolated dorsal striata from the eight inbred founder CC strains (Supplementary Table S1). In total, dopamine from 102 mice at the age of 3 months was measured by GC-MS. DA levels varied significantly across the founders (one-way ANOVA, $\mathrm{p}=0.0004, \mathrm{~F}=4.507$ ), indicating strain-specific differences in DA levels in the nigrostriatal dopaminergic circuit (Figure 1). PWK/PhJ, A/J, and NOD/LtJ strains showed the lowest levels of DA, while the highest levels were detected in NZO/HILtJ, CAST/EiJ, and C57BL/6J mice. Thus, striatal DA levels appear to be under genetic control.

To investigate if variation in DA level is indeed inheritable, we measured the striatal DA level across 32 strains of CC mice. In total, we analysed $327 \mathrm{CC}$ mice with similar number of mice from both sexes. The CC strains showed considerable variation in DA levels with a range of around $10 \mathrm{pmol} / \mathrm{mg}$ in both sexes (Figure 2). From these values, the estimated 
Thomas et al:: Genetic Regulators of Nigrostriatal Circuit

broad-sense heritability $\left(\mathrm{H}^{2}\right)$ was calculated to be 0.52 , indicating the DA level differences are inheritable, and associated genetic variation could be detected by QTL mapping. (Hegmann and Possidente, 1981) (see Methods for details).

\section{QTL mapping associates a genomic locus on chromosome $\mathrm{X}$ with striatal dopamine} levels

Identifying novel genetic regulators associated with striatal DA levels could help better understand the development of dopaminergic circuits and susceptibility to diseases, like PD. Therefore, to leverage the power of $\mathrm{CC}$ strains to identify trait-associated genetic loci at a good resolution, we performed QTL mapping based on the measured DA levels across the 32 CC strains. The mapping was performed separately for males and females, and the genomewide significance results for all genetic markers are presented in Figure 3 and Supplementary Table S2. QTL mapping using the female data identified one genetic marker located on chromosome $\mathrm{X}$ at position 144.300241 Mb to be associated with DA levels, when applying the $95^{\text {th }}$ percentile threshold for genome-wide significance $\left(-\log _{10}\right.$ p-value $\left.=5.23\right)$ (Figure 3A). However, additional adjacent markers at downstream positions of $157.823410 \mathrm{Mb}$ and 158.259643 $\mathrm{Mb}$ were also highly associated in females $\left(-\log _{10} \mathrm{p}\right.$-value $=4.96$ for both markers), while an upstream marker at position $136.176403 \mathrm{Mb}$ showed strong association in males $(-\log 10 \mathrm{p}$-value $=4.91)$. Taken together, our QTL analysis identifies of a combined region spanning over $32 \mathrm{Mb}$ with high association to striatal DA levels on chromosome $\mathrm{X}$.

\section{Col4a6 is a developmental gene with altered expression between mouse strains}


Thomas et al:: Genetic Regulators of Nigrostriatal Circuit

The identified locus from position $131 \mathrm{Mb}$ to $163 \mathrm{Mb}$ on chromosome $\mathrm{X}$ includes 393 genes that could potentially be underlying the association with striatal DA levels. However, the vast majority $(>95 \%)$ of trait-associated genetic variants are located outside of protein-coding genomic regions (Maurano et al., 2012). Recent advances in functional genomics analysis have revealed these non-coding variants to be highly enriched in gene regulatory regions such as enhancers where they can disrupt transcription factor binding and alter the target gene expression. Therefore, we asked whether such cis-regulatory variants could be affecting gene expression at our locus of interest in the $\mathrm{SN}$ of the midbrain, from where the DA neurons project to the dorsal striatum. To this aim, we took advantage of our recent transcriptomic profiling of ventral midbrains from C57BL/6J and A/J mice (Gui et al., 2020), two CC founder strains with significantly different levels of striatal DA (Figure 1, p=0.026, unpaired t-test). These two strains are also widely used laboratory mouse strains and have one of the largest difference in striatal dopamine (see above). Using the RNA-seq data we plotted the absolute $\log _{2}$-fold change for all 393 genes between C57BL/6J and A/J to identify those with altered gene expression (Figure 4A). Interestingly, only 24 genes showed significant differential gene expression (Supplementary Table S3). By far the largest fold change of all protein-coding genes was found for Collagen $4 a 6$ (Col4a6) gene, which showed over 9-fold difference between the 2 strains. The transcriptomic analysis was based on a total 24 mice, 12 from each strain and sex, with A/J displaying a significant reduction for Col4a6 in both females and males compared to age-matched C57BL/6J (Figure 4B), consistent with a lower level of DA in the striatum of $\mathrm{A} / \mathrm{J}$ (Figure 1).

While Col4a6 expression was significantly lower in $\mathrm{A} / \mathrm{J}$, the overall abundance of expression in the adult $\mathrm{C} 57 \mathrm{BL} / 6 \mathrm{~J}$ midbrain was also very low $(<0.3 \mathrm{RPKM})$, indicating that, in adult mice, its expression is limited to only one or a few cell types, most likely endothelial cells, which have been reported to produce collagens (Gelse et al., 2003; Ricard-Blum, 2011). 
Thomas et al:: Genetic Regulators of Nigrostriatal Circuit

Collagen IV is an essential and abundant component of the basement membrane (Mao et al., 2015). In the nervous system, its function has been associated with axon guidance and neurite outgrowth in non-mammal model systems (Takeuchi et al., 2015; Mirre et al., 1992), and in cultured sympathetic neurons (Firla, 1990). The two angles of collagen IV function in the nervous system (regulation of neurogenesis and of neurite outgrowth and guidance) are probably intertwined.

To get a better idea about the cellular source of COLAA6 during development, we observed its expression in published single cell RNA-seq (scRNA-seq) data corresponding to 26 cell types of the developing human midbrain (La Manno et al., 2016). COLAA6 expression was highest in floor plate progenitors and selected subtypes radial glia-like cells, with very low expression detected in other cell types (Figure 4C). The expression profile of COLAA6 closely followed the expression of SOX2, a key regulator of neurogenesis (Ferri et al., 2004). Consistently, previous screens for primary SOX2 target genes have found COLAA6 expression to depend on SOX2 (Fang et al., 2011; Berezovsky et al., 2014).

Taken together, the expression profile of COLAA6 implicates it as a developmental gene and its dependence on SOX2 indicates a possible role in neurogenesis. Indeed, previous work has shown that the zebrafish orthologs of type IV collagens, col4a5 and col4a6, can control proper axonal guidance during zebrafish development (Takeuchi et al., 2015).

\section{Differences in striatal axonal branching between $\mathrm{C57BL/6J}$ and $\mathrm{A} / \mathrm{J}$ mice}

Based on the observed differences in striatal DA levels, the localization of Col4a6 gene in the associated QTL, the distinct neurodevelopmental expression profile of COLAA6, and the previously described role of collagen IV in neurite outgrowth and guidance (see above), we hypothesized that DAn axonal fiber density could be altered specifically in the striatum of the 
Thomas et al:: Genetic Regulators of Nigrostriatal Circuit

mouse strains. To test this, we performed TH immunostaining on brain sections from the two founder strains $\mathrm{C} 57 \mathrm{BL} / 6 \mathrm{~J}$ and A/J. The percentage of area occupied by $\mathrm{TH}$ in the DAn projection areas (dorsal striatum for SN and piriform cortex and amyglada for VTA) was used to compare axonal fiber density between the strains. Interestingly, 3-month-old A/J mice showed 29\% lower TH fiber density in dorsal striatum compared to C57BL/6J (unpaired ttest, $\mathrm{p}=0.0059$ ), consistent with lower DA levels in A/J (Figure 5). No such differences could be observed in amygdala or in piriform cortex, suggesting that the differences observed between the two mouse strains appear to be specific to the dorsal striatum.

To determine if the number of DAn differed between C57BL/6J and A/J mice, we estimated the amount of these neurons in the 2 strains as described in Materials and Methods. We observed no difference in the number of TH-positive neurons between the two strains, implying that differences observed in striatal $\mathrm{TH}$ positive axons reflect a difference in branching of DAn, rather than their number of the SN (Figure 5). Hence, our data points to a role of COL4A6 in modulation of the branching of DAn of the SN, but not that of DAn of the VTA.

Taken together, our QTL analysis allowed us to identify Col4a6 as a new gene putatively involved in the DAns neurogenesis and axonal branching in the dorsal striatum.

\section{Discussion}

While the DAns residing in the $\mathrm{SN}$ are of central interest to translational neuroscience research because of their unique properties that renders them susceptible (Surmeier, 2018), a lot of the mechanisms surrounding their basic properties remain unknown. 
Thomas et al:: Genetic Regulators of Nigrostriatal Circuit

In this study, we used CC strains to identify QTL and new candidate genes regulating the integrity of the nigrostriatal circuitry. The variations of striatal dopamine levels between CC strains demonstrate an inheritable part of this trait, which could also underlie the variability in human populations. Together with previous transcriptomic data in the midbrain of two founder strains, our results point to Col4a6 playing an important role in neurogenesis and axonal branching of striatal DAns.

Despite the success of human GWAS methodologies to decipher phenotype-genotype associations, human tools lack proper standardized and controlled conditions. To overcome these limitations, CC mouse strains were generated to provide a model for heterogeneous human population (Churchill et al., 2004). Genetic diversity of CC mouse model provides more precise QTL mapping results than conventional mapping populations. The wide phenotypic range of around $10 \mathrm{pmol} / \mathrm{mg}$ DA enabled us to map a significant QTL of about 32 $\mathrm{Mb}$ with a reasonable number of $32 \mathrm{CC}$ strains and eight founder strains. Our previous transcriptomic analysis coming from two CC founders with significantly different levels of striatal DA (Gui et al., 2020) provide useful data to narrow the QTL on chromosome X to 24 DEG, Col4a6 showing a 9-fold difference in C57BL/6J compared to A/J, two of the CC founder strains that had one of the largest striatal DA differences. To find out more about the role of Col4a6 in this brain region, we started to look at data available from the developing human midbrain (La Manno et al., 2016), which suggests an important role of Col4a6 in the DAns neurogenesis. Collagen IV alpha- 6 chain is one of the six subunits of type IV collagen, a major component of basement membranes. Collagen IV is a member of the collagen family of glycoproteins, which themselves are constituents of the extracellular matrix (ECM), and among the most abundant proteins in the animal kingdom (Vecino and Kwok, 2016). ECM proteins, in particular collagens, in the nervous system play key roles in development, in cellular maintenance and repair, and in tissue responses to diseases involving injury or 
Thomas et al:: Genetic Regulators of Nigrostriatal Circuit

neoplasia (Rutka et al., 1988). Collagens in the PNS provide a scaffold for Schwann cells and support neurite outgrowth (Lein et al., 1991; Chen et al., 2015). As stated above, a central role for collagen IV in axon guidance and neurite outgrowth is also supported by studies in simple model organisms (Mirre et al., 1992; Takeuchi et al., 2015). Collagens, including type IV, in the nervous system are produced primarily by cells of mesodermal origin, the endothelial cells, and are found, together with other forms ECM proteins, in the basement membrane of cerebral blood vessels and at the glia limitans (Rutka et al., 1988). Upon injury, collagen expression and secretion together with that of other ECM proteins, by glial cells appears (Liesi and Kauppila, 2002). While evidence suggest that, in some scenarios, this process is supportive of neurite outgrowth (see above), in rats, by contributing to the formation of the glial scar, it is thought to inhibit axonal regeneration (Liesi and Kauppila, 2002). Interestingly though, engineered biopolymer scaffolds containing collagen are being explored as therapeutic support for nerve repair after injury (Li and Dai, 2018). Thus, the role of collagens in neuronal maintenance and repair may depend on a complex balance of opposing actions.

Our study shows for the first time that one subunit of collagen IV, subunit 6 , is a candidate for regulating axonal branching in the CNS of a mammal. Because we had already observed large striatal DA differences and large midbrain Col4a6 expression differences in $\mathrm{C} 56 \mathrm{BL} / \wedge \mathrm{J}$ versus $\mathrm{A} / \mathrm{J}$ mice, we then tested if these two mouse strains also showed differences in striatal axonal branching. We therefore measured TH-positive axons in the dorsal striatum C57BL/6J and $\mathrm{A} / \mathrm{J}$ by quantitative immunofluorescence. We observed less TH-positive axons in the dorsal striatum of $\mathrm{A} / \mathrm{J}$ compared to $\mathrm{C} 57 \mathrm{BL} / 6 \mathrm{~J}$ mice. The determine if this was due to a difference in the number of $\mathrm{TH}$ positive neurons in the SN between these two strains, we also estimated those numbers, but did not find a difference. Thus, the lower TH-positive axons we observe in the striata of $\mathrm{A} / \mathrm{J}$ mice most likely reflect a lesser axonal branching of the DAns. 
Thomas et al:: Genetic Regulators of Nigrostriatal Circuit

To ensure that our strain differences affect the nigrostriatal circuitry and not all projecting DAns of the midbrain, we assessed brain areas that receive projections from the VTA. Based on our results from the amygdala and piriform cortex, phenotypic differences observed in the striata of $\mathrm{C} 57 \mathrm{BL} / 6 \mathrm{~J}$ and $\mathrm{A} / \mathrm{J}$ are not present in the other midbrain dopaminergic circuits. Other studies indicate that more factors regulating nigrostriatal integrity remain to be found. Studying mouse strains other than those used in our study, Baker et al., 1980 (Baker et al., 1980) and Zaborsky et al., 2001 (Zaborszky and Vadasz, 2001) reported strain-dependent differences in the number of midbrain populations of DAns. On a functional level, other studies found strain-specific differences in motor behaviour, such as lower motor activity, balance and exploratory skills displayed by A/J compared to C57BL/6J (Jong et al., 2010). Finally, recent studies showed significant effect of the genetic background on locomotor behaviour (Schoenrock et al., 2020) and response to cocaine (Schoenrock et al., 2018) using recombinant inbred intercrosses generated from $\mathrm{CC}$ strains, illustrating how the $\mathrm{CC}$ strains can serve as useful model for identifying further QTLs and genetic variants that govern structure and function of DAn's.

In this study, using a combination of biochemical and neuropathological analyses combined with QTL mapping in the CC mouse population, we highlight Col4a6 as a new gene candidate regulating the axonal branching in the nigrostriatal dopaminergic system of mammals. Because these are the structures that are affected early in PD (Kordower et al., 2013), we propose that a better understanding of the actions of collagen IV on these neurons may open the way for novel neuroprotection therapies.

\section{Funding}


Thomas et al:: Genetic Regulators of Nigrostriatal Circuit

LS and MB would like to thank the Luxembourg National Research Fund (FNR) for the support (FNR CORE C15/BM/10406131 grant). MM would like to thank the Luxembourg National Research Fund (FNR) for the support (FNR PEARL P16/BM/11192868 grant). KS would like to thank the support by intra-mural grants from the Helmholtz-Association (Program Infection and Immunity).

\section{Acknowledgements}

We would like to thank Drs Aurélien Ginolhac and Anthoula Gaigneaux for their support with bioinformatic analysis and EMBL Gene Core at Heidelberg for support with highthroughput sequencing, and Dr Djalil Coowar (Animal Facility of University of Luxembourg) for help with breeding of experimental mice. KS would like to thank the animal caretakers at the Central Animal Facilities of the HZI for maintaining the mice. The computational analysis presented in this paper were carried out using the HPC facilities of the University of Luxembourg (68).

\section{References}

Ashrafi A, Garcia P, Kollmus H, Schughart K, Del Sol A, Buttini M, Glaab E (2017) Absence of regulator of G-protein signaling 4 does not protect against dopamine neuron dysfunction and injury in the mouse 6-hydroxydopamine lesion model of Parkinson's disease. Neurobiology of aging 58:30-33.

Baker H, Joh TH, Reis DJ (1980) Genetic control of number of midbrain dopaminergic neurons in inbred strains of mice: relationship to size and neuronal density of the striatum. Proceedings of the National Academy of Sciences of the United States of America 77:4369-4373.

Belknap JK (1998) Effect of within-strain sample size on QTL detection and mapping using recombinant inbred mouse strains. Behavior genetics 28:29-38.

Berezovsky AD, Poisson LM, Cherba D, Webb CP, Transou AD, Lemke NW, Hong X, Hasselbach LA, Irtenkauf SM, Mikkelsen T, deCarvalho AC (2014) Sox2 promotes 
Thomas et al:: Genetic Regulators of Nigrostriatal Circuit

malignancy in glioblastoma by regulating plasticity and astrocytic differentiation. Neoplasia (New York, N.Y.) 16:193-206, 206.e19-25.

Brooks SP, Pask T, Jones L, Dunnett SB (2004) Behavioural profiles of inbred mouse strains used as transgenic backgrounds. I: motor tests. Genes, brain, and behavior 3:206-215.

Cabib S, Puglisi-Allegra S, Ventura R (2002) The contribution of comparative studies in inbred strains of mice to the understanding of the hyperactive phenotype. Behavioural brain research 130:103-109.

Chen P, Cescon M, Bonaldo P (2015) The Role of Collagens in Peripheral Nerve Myelination and Function. Molecular neurobiology 52:216-225.

Churchill GA et al. (2004) The Collaborative Cross, a community resource for the genetic analysis of complex traits. Nature genetics 36:1133-1137.

Del Rey NL-G, Quiroga-Varela A, Garbayo E, Carballo-Carbajal I, Fernández-Santiago R, Monje MHG, Trigo-Damas I, Blanco-Prieto MJ, Blesa J (2018) Advances in Parkinson's Disease: 200 Years Later. Frontiers in neuroanatomy 12:113.

Fang X, Yoon J-G, Li L, Yu W, Shao J, Hua D, Zheng S, Hood L, Goodlett DR, Foltz G, Lin B (2011) The SOX2 response program in glioblastoma multiforme: an integrated ChIPseq, expression microarray, and microRNA analysis. BMC genomics 12:11.

Ferri ALM, Cavallaro M, Braida D, Di Cristofano A, Canta A, Vezzani A, Ottolenghi S, Pandolfi PP, Sala M, DeBiasi S, Nicolis SK (2004) Sox2 deficiency causes neurodegeneration and impaired neurogenesis in the adult mouse brain. Development (Cambridge, England) 131:3805-3819.

Firla MT (1990) Asthetische Aspekte zur biomimetischen Schichttechnik. Zahnarztliche Mitteilungen 80:1957-1962.

Gelse K, Pöschl E, Aigner T (2003) Collagens--structure, function, and biosynthesis. Advanced drug delivery reviews 55:1531-1546.

Gilgun-Sherki Y, Djaldetti R, Melamed E, Offen D (2004) Polymorphism in candidate genes: implications for the risk and treatment of idiopathic Parkinson's disease. The pharmacogenomics journal 4:291-306.

Gui Y, Thomas MH, Garcia P, Karout M, Halder R, Michelucci A, Kollmus H, Zhou C, Melmed S, Schughart K, Balling R, Mittelbronn M, Nadeau JH, Williams RW, Sauter T, Buttini M, Sinkkonen L (2020) Pituitary Tumor Transforming Gene 1 orchestrates gene regulatory variation in mouse ventral midbrain during aging.

Hamre K, Tharp R, Poon K, Xiong X, Smeyne RJ (1999) Differential strain susceptibility following 1-methyl-4-phenyl-1,2,3,6-tetrahydropyridine (MPTP) administration acts in an autosomal dominant fashion: quantitative analysis in seven strains of Mus musculus. Brain research 828:91-103.

Hassan A, Benarroch EE (2015) Heterogeneity of the midbrain dopamine system: Implications for Parkinson disease. Neurology 85:1795-1805.

Hegmann JP, Possidente B (1981) Estimating genetic correlations from inbred strains. Behavior genetics 11:103-114.

Ingram DK, London ED, Reynolds MA, Waller SB, Goodrick CL (1981) Differential effects of age on motor performance in two mouse strains. Neurobiology of aging 2:221-227.

Jaeger C, Glaab E, Michelucci A, Binz TM, Koeglsberger S, Garcia P, Trezzi J-P, Ghelfi J, Balling R, Buttini M (2015) The mouse brain metabolome: region-specific signatures and response to excitotoxic neuronal injury. The American journal of pathology 185:16991712. 
Thomas et al:: Genetic Regulators of Nigrostriatal Circuit

Jäger C, Hiller K, Buttini M (2016) Metabolic Profiling and Quantification of Neurotransmitters in Mouse Brain by Gas Chromatography-Mass Spectrometry. Current protocols in mouse biology 6:333-342.

Jankovic J, McDermott M, Carter J, Gauthier S, Goetz C, Golbe L, Huber S, Koller W, Olanow C, Shoulson I (1990) Variable expression of Parkinson's disease: a base-line analysis of the DATATOP cohort. The Parkinson Study Group. Neurology 40:15291534.

Jong S de, Fuller TF, Janson E, Strengman E, Horvath S, Kas MJH, Ophoff RA (2010) Gene expression profiling in $\mathrm{C} 57 \mathrm{BL} / 6 \mathrm{~J}$ and $\mathrm{A} / \mathrm{J}$ mouse inbred strains reveals gene networks specific for brain regions independent of genetic background. BMC genomics 11:20.

Kalinderi K, Fidani L, Katsarou Z, Bostantjopoulou S (2011) Pharmacological treatment and the prospect of pharmacogenetics in Parkinson's disease. International journal of clinical practice 65:1289-1294.

Kaplan N, Vituri A, Korczyn AD, Cohen OS, Inzelberg R, Yahalom G, Kozlova E, Milgrom R, Laitman Y, Friedman E, Rosset S, Hassin-Baer S (2014) Sequence variants in SLC6A3, DRD2, and BDNF genes and time to levodopa-induced dyskinesias in Parkinson's disease. Journal of molecular neuroscience : MN 53:183-188.

Kordower JH, Olanow CW, Dodiya HB, Chu Y, Beach TG, Adler CH, Halliday GM, Bartus RT (2013) Disease duration and the integrity of the nigrostriatal system in Parkinson's disease. Brain : a journal of neurology 136:2419-2431.

La Manno G, Gyllborg D, Codeluppi S, Nishimura K, Salto C, Zeisel A, Borm LE, Stott SRW, Toledo EM, Villaescusa JC, Lönnerberg P, Ryge J, Barker RA, Arenas E, Linnarsson S (2016) Molecular Diversity of Midbrain Development in Mouse, Human, and Stem Cells. Cell 167:566-580.e19.

Lein PJ, Higgins D, Turner DC, Flier LA, Terranova VP (1991) The NC1 domain of type IV collagen promotes axonal growth in sympathetic neurons through interaction with the alpha 1 beta 1 integrin. The Journal of cell biology 113:417-428.

Li X, Dai J (2018) Bridging the gap with functional collagen scaffolds: tuning endogenous neural stem cells for severe spinal cord injury repair. Biomaterials science 6:265-271.

Liesi P, Kauppila T (2002) Induction of type IV collagen and other basement-membraneassociated proteins after spinal cord injury of the adult rat may participate in formation of the glial scar. Experimental neurology 173:31-45.

Mao M, Alavi MV, Labelle-Dumais C, Gould DB (2015) Type IV Collagens and Basement Membrane Diseases: Cell Biology and Pathogenic Mechanisms. Current topics in membranes 76:61-116.

Masliah E, Rockenstein E, Veinbergs I, Mallory M, Hashimoto M, Takeda A, Sagara Y, Sisk A, Mucke L (2000) Dopaminergic loss and inclusion body formation in alpha-synuclein mice: implications for neurodegenerative disorders. Science (New York, N.Y.) 287:12651269.

Maurano MT et al. (2012) Systematic localization of common disease-associated variation in regulatory DNA. Science (New York, N.Y.) 337:1190-1195.

Mirre C, Le Parco Y, Knibiehler B (1992) Collagen IV is present in the developing CNS during Drosophila neurogenesis. Journal of neuroscience research 31:146-155.

Nadeau JH, Auwerx J (2019) The virtuous cycle of human genetics and mouse models in drug discovery. Nature reviews. Drug discovery 18:255-272. 
Thomas et al:: Genetic Regulators of Nigrostriatal Circuit

Nagatsu T, Nakashima A, Ichinose H, Kobayashi K (2019) Human tyrosine hydroxylase in Parkinson's disease and in related disorders. Journal of neural transmission (Vienna, Austria : 1996) 126:397-409.

Peters LL, Robledo RF, Bult CJ, Churchill GA, Paigen BJ, Svenson KL (2007) The mouse as a model for human biology: a resource guide for complex trait analysis. Nature reviews. Genetics 8:58-69.

Ricard-Blum S (2011) The collagen family. Cold Spring Harbor perspectives in biology 3:a004978.

Rutka JT, Apodaca G, Stern R, Rosenblum M (1988) The extracellular matrix of the central and peripheral nervous systems: structure and function. Journal of neurosurgery 69:155170.

Schindelin J, Arganda-Carreras I, Frise E, Kaynig V, Longair M, Pietzsch T, Preibisch S, Rueden C, Saalfeld S, Schmid B, Tinevez J-Y, White DJ, Hartenstein V, Eliceiri K, Tomancak P, Cardona A (2012) Fiji: an open-source platform for biological-image analysis. Nature methods 9:676-682.

Schoenrock SA et al. (2020) Characterization of genetically complex Collaborative Cross mouse strains that model divergent locomotor activating and reinforcing properties of cocaine. Psychopharmacology 237:979-996.

Schoenrock SA, Oreper D, Farrington J, McMullan RC, Ervin R, Miller DR, Pardo-Manuel de Villena F, Valdar W, Tarantino LM (2018) Perinatal nutrition interacts with genetic background to alter behavior in a parent-of-origin-dependent manner in adult Collaborative Cross mice. Genes, brain, and behavior 17:e12438.

Surmeier DJ (2018) Determinants of dopaminergic neuron loss in Parkinson's disease. The FEBS journal 285:3657-3668.

Takeuchi M, Yamaguchi S, Yonemura S, Kakiguchi K, Sato Y, Higashiyama T, Shimizu T, Hibi M (2015) Type IV Collagen Controls the Axogenesis of Cerebellar Granule Cells by Regulating Basement Membrane Integrity in Zebrafish. PLoS genetics 11:e1005587.

Vadasz C, Sziraki I, Sasvari M, Kabai P, Murthy LR, Saito M, Laszlovszky I (1998) Analysis of the mesotelencephalic dopamine system by quantitative-trait locus introgression. Neurochemical research 23:1337-1354.

Vadász C, Sziráki I, Murthy LR, Vadász I, Badalamenti AF, Kóbor G, Lajtha A (1987) Genetic determination of mesencephalic tyrosine hydroxylase activity in the mouse. Journal of neurogenetics 4:241-252.

van Rooden SM, Colas F, Martínez-Martín P, Visser M, Verbaan D, Marinus J, Chaudhuri RK, Kok JN, van Hilten JJ (2011) Clinical subtypes of Parkinson's disease. Movement disorders : official journal of the Movement Disorder Society 26:51-58.

Vecino E, Kwok JCF (2016) The Extracellular Matrix in the Nervous System: The Good and the Bad Aspects. In: Composition and Function of the Extracellular Matrix in the Human Body (Travascio F, ed): InTech.

Vogt Weisenhorn DM, Giesert F, Wurst W (2016) Diversity matters - heterogeneity of dopaminergic neurons in the ventral mesencephalon and its relation to Parkinson's Disease. Journal of neurochemistry 139 Suppl 1:8-26.

Zaborszky L, Vadasz C (2001) The midbrain dopaminergic system: anatomy and genetic variation in dopamine neuron number of inbred mouse strains. Behavior genetics 31:4759. 
Thomas et al:: Genetic Regulators of Nigrostriatal Circuit

\section{Figure Legends}

Figure 1. Striatal dopamine levels measured in the different Collaborative Cross (CC) founders. (A) Schematic representation of the experimental set-up. (B) Level of dopamine measured by GC-MS in the striatum of the different CC founders, expressed relative to the dopamine level of the common C57BL/6J strain. Data are expressed in mean \pm standard deviation and the significance of differences was tested with one-way ANOVA ( $p=0.0004$, $\mathrm{F}=4.507)$.

Figure 2. Striatal dopamine levels measured in the different collaborative cross (CC) strains. Levels of dopamine measured by GC-MS in the striatum of the different CC strains, expressed in $\mathrm{pg} / \mathrm{mg}$ of tissue (mean \pm standard deviation) and the significance of differences was tested with one-way ANOVA. (A) Level of dopamine in the striatum of CC males $(p<0.0001, F=3.964)$. (B) Level of dopamine in the striatum of CC females $(p<0.0001$, $\mathrm{F}=7.435)$.

Figure 3. QTL mapping for dorsal striatum dopamine levels in CC strains. Plots show $\log _{10}$ p-values (y-axis) of genetic markers across chromosome locations (x-axis). Horizontal dashed lines represent the $95^{\text {th }}$ percentile thresholds for genome-wide significance. (A) QTL mapping with female CC strains yielded the most significant QTL at chromosome X 144.3 $\mathrm{Mb}$ with $-\log (\mathrm{P})$ 5.23. (B) QTL mapping with male CC strains yielded the most significant QTL at chromosome X 136.2 Mb with $-\log (\mathrm{P}) 4.91$.

Figure 4. Col4a6 is the gene with highest differential expression between C57BL/6J and A/J at the identified chromosome X QTL. (A) Log2-fold changes of genes in chromosome 
Thomas et al:: Genetic Regulators of Nigrostriatal Circuit

$\mathrm{X}$ locus between $131 \mathrm{Mb}$ and $163 \mathrm{MB}$. Genes with adjusted p-value below 0.05 are labelled in red. (B) The expression (RPKM) of Col4a6 in the ventral midbrain of C57BL/6J and A/J. (C) The expression of Col4a6 and Sox 2 during human midbrain during development based on scRNA-seq data from La Manno et al (La Manno et al., 2016). The two genes show similar expression profiles. Cell types are named with "h" to indicate human: Endo, endothelial cells ; Peric, pericytes; Mgl, microglia; OPC, oligodendrocyte precursor cells; Rgl1-3, radial glialike cells; NProg, neuronal progenitor; Prog, progenitor medial floorplate (FPM), lateral floorplate (FPL), midline (M), basal plate (BP); NbM, medial neuroblast; NbML1\&5, mediolateral neuroblasts; RN, red nucleus; DA0-2, dopaminergic neurons; Gaba, GABAergic neurons; Sert, serotonergic; OMTN, oculomotor and trochlear nucleus.

Figure 5. Measure of tyrosine hydroxylase (TH) by immunofluorescence in the brain of 3-month-old C57BL/6J and A/J. (A, B) TH in striatum. (C, D) TH in amygdala. (E, F) TH in piriform cortex. $(\mathrm{G}, \mathrm{H}) \mathrm{TH}$ in substantia nigra. (A, C, E) Images of $\mathrm{TH}$ stainings in striatum, amygdala and piriform cortex, magnification 40X. Scales bar: $50 \mu \mathrm{m}(\mathrm{G})$ Images of TH stainings in substantia nigra, magnification 10X. Scale bar: $200 \mu \mathrm{m}$ (B, D, F) Quantification of the percentage area occupied by TH from stainings in striatum, amygdala and piriform cortex. $(\mathrm{H})$ Quantification of the TH-positive area in substantia nigra. Data are expressed in mean \pm standard deviation and were analysed with unpaired t-test $(\mathrm{p}=0.0059$ in the striatum $(* *), p=0.47$ in amygdala, $\mathrm{p}=0.43$ in piriform cortex and $\mathrm{p}=0.78$ in $\mathrm{SN}$ ). 
Figure 1

A bioRxiv preprint doi: https://doi.org/10.1101/2020.06.28.176206; this version posted June 28, 2020. The copyright holder for this preprint (which was not certified by peer review) is the author/funder. All rights reserved. No reuse allowed without permission.

$\bigcirc \mathrm{C} 57 \mathrm{BL} / 6 \mathrm{~J}$

$\bigcirc A / J$

$\bigcirc 129 S 1 /$ SvImJ

$\bigcirc N O D / L t J$ $\bigcirc \mathrm{NZO} / \mathrm{HILtJ}$

CAST/EiJ

$\mathrm{PWK} / \mathrm{PhJ}$

WSB/EiJ

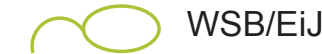

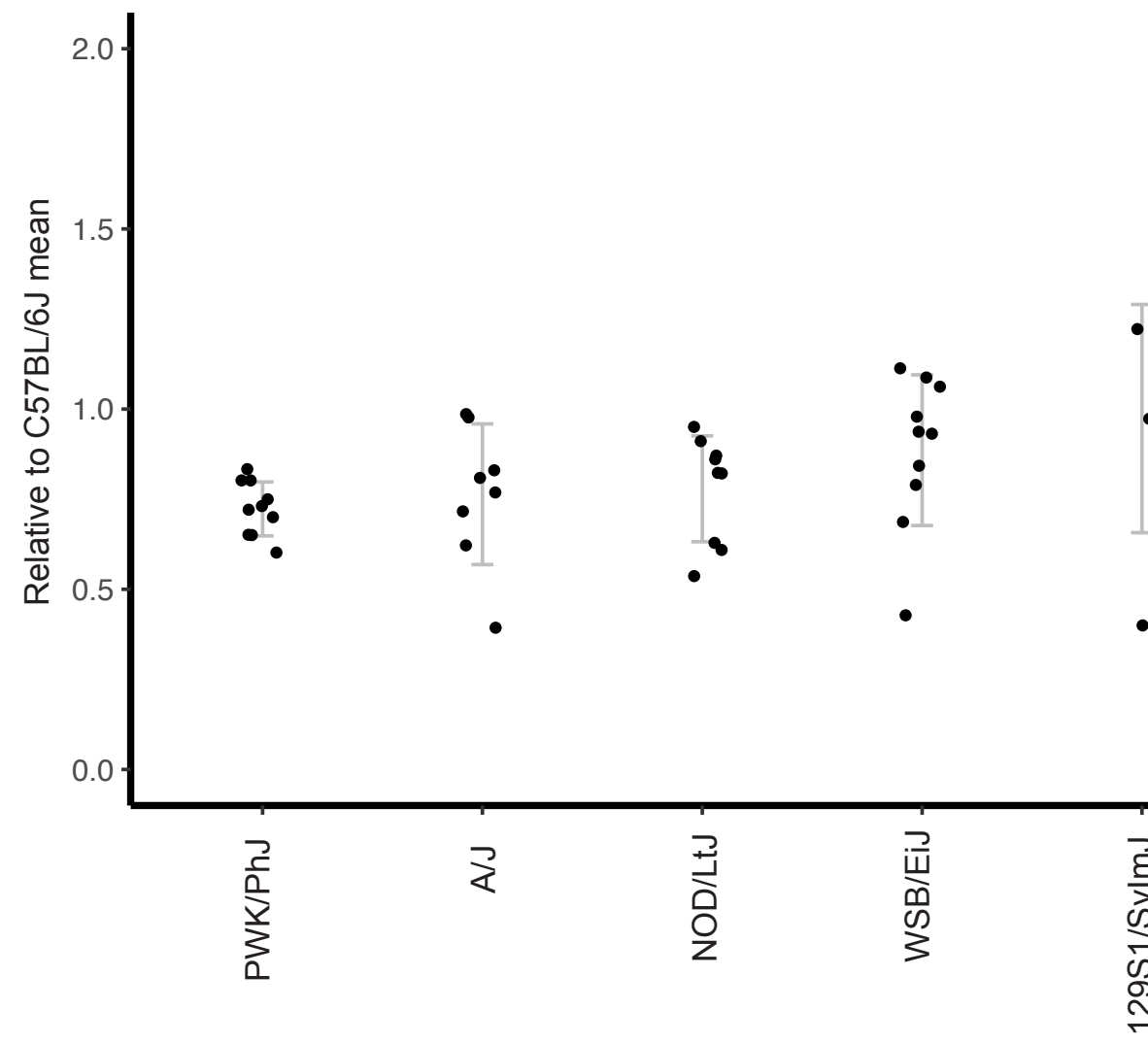

GC-MS measuring dopamine concentration in dorsal striatum
Dorsal striatum

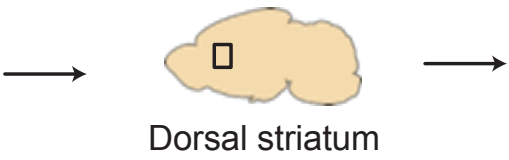

\begin{tabular}{|c|c|c|c|}
\hline 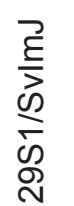 & 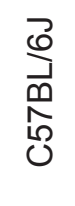 & 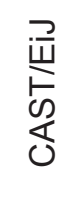 & $\begin{array}{l}\stackrel{P}{P} \\
\stackrel{\equiv}{I} \\
\text { N }\end{array}$ \\
\hline
\end{tabular}


Figure 2

A Striatal Dopamine Concentration of 32 CC strains bioRxiv preprint doi: https://doi.org/10.1101/2020.06.28.176206 (which was not certified by peer review) is the author

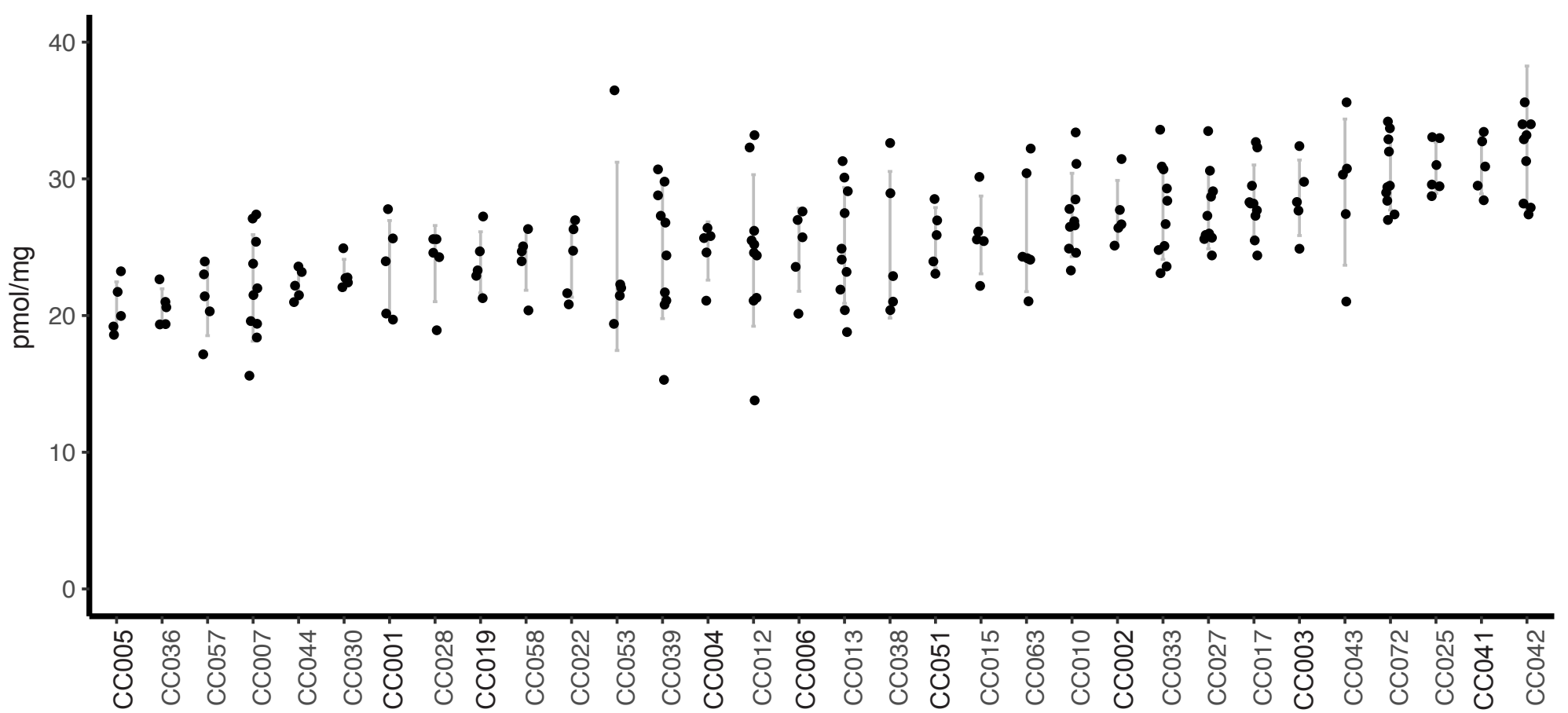

B Striatal Dopamine Concentration of 32 CC strains 3-month female

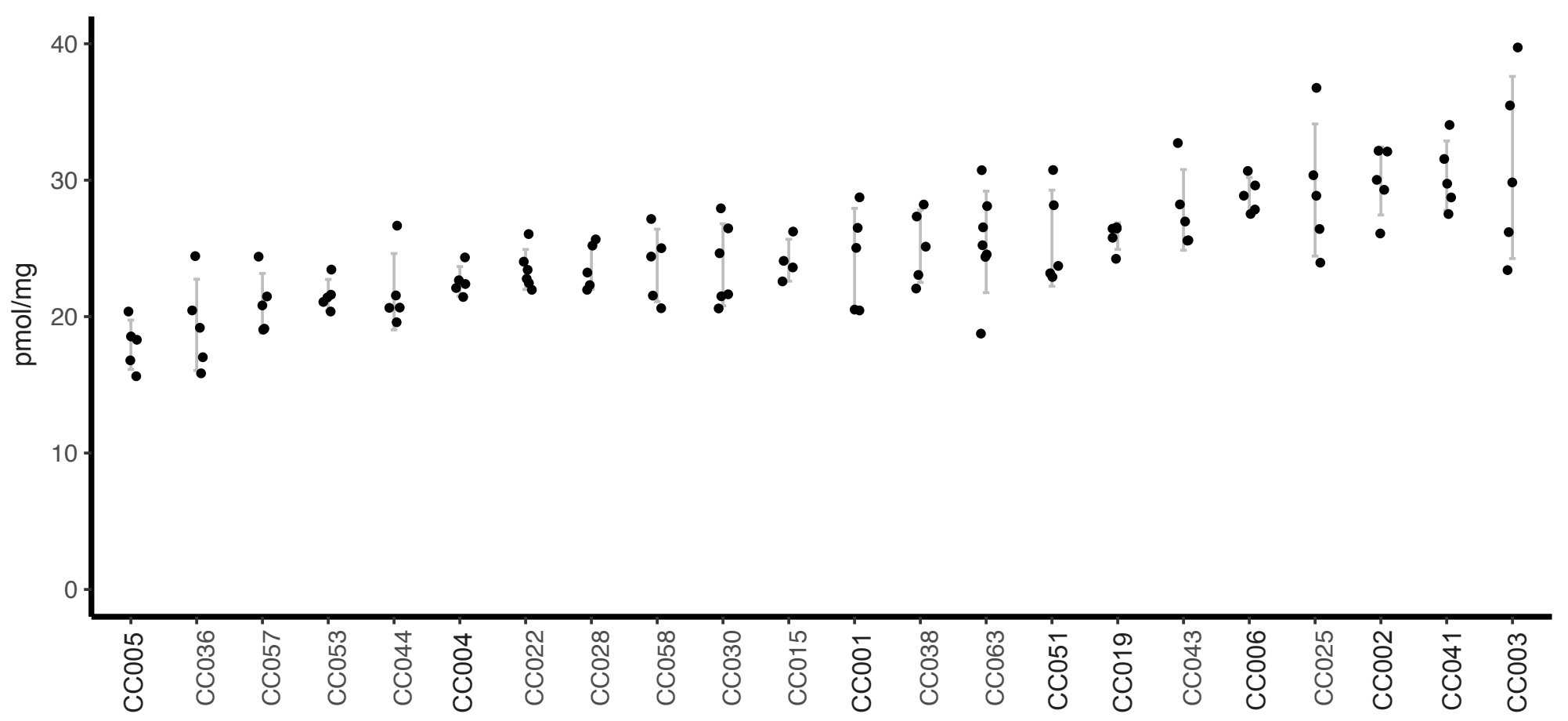


Figure 3

A

QTL mapping with female CC strains
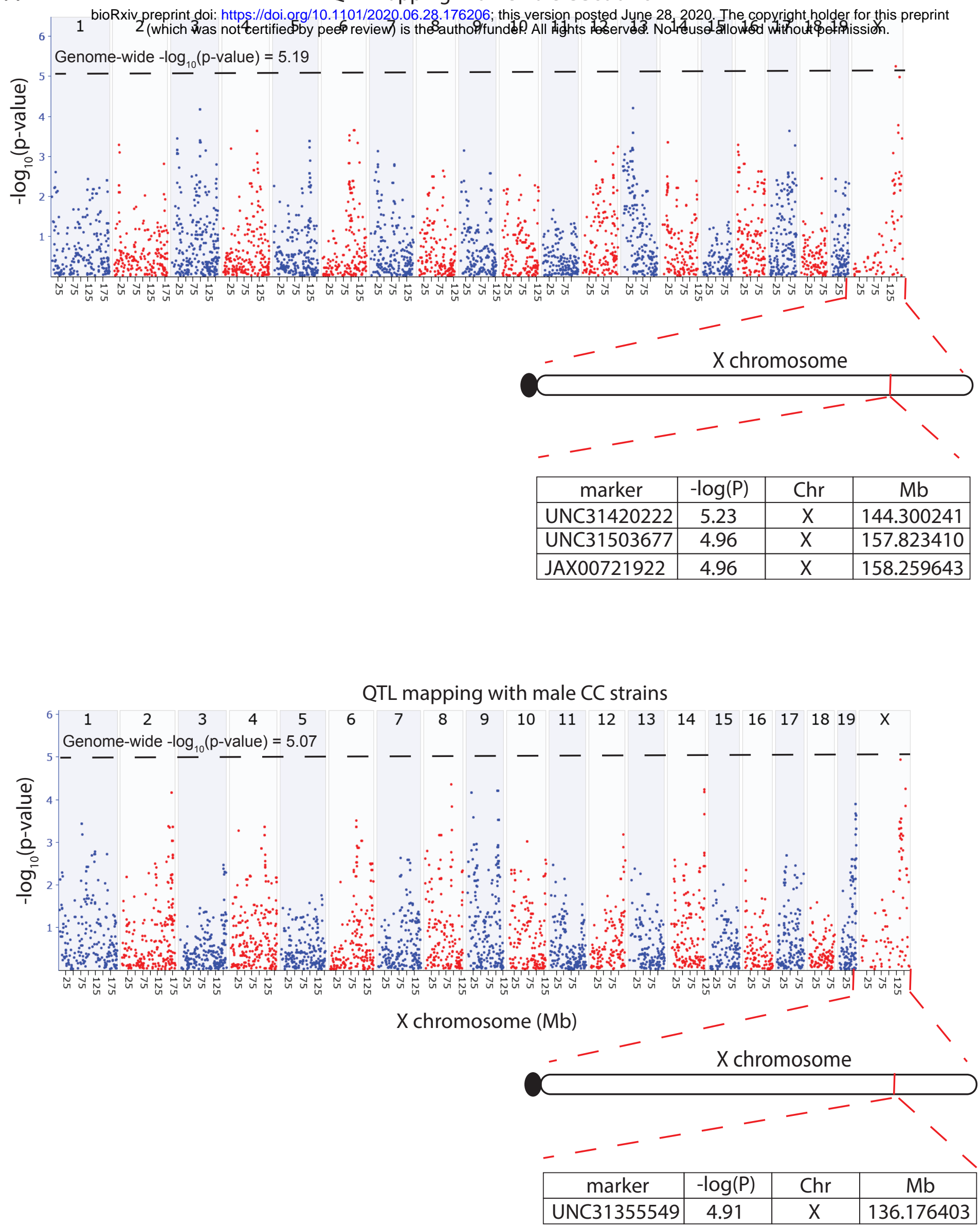
Figure 4

A
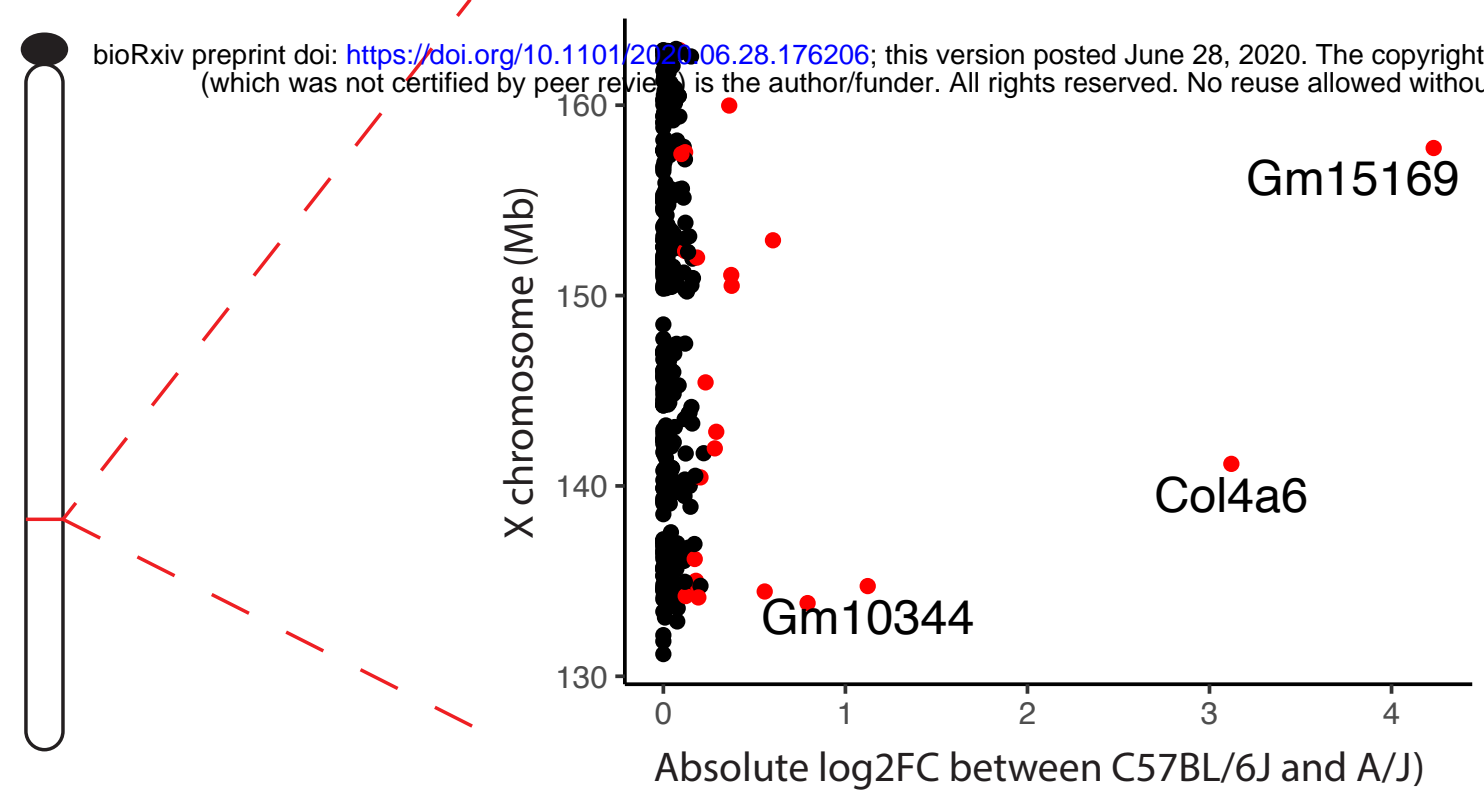

B

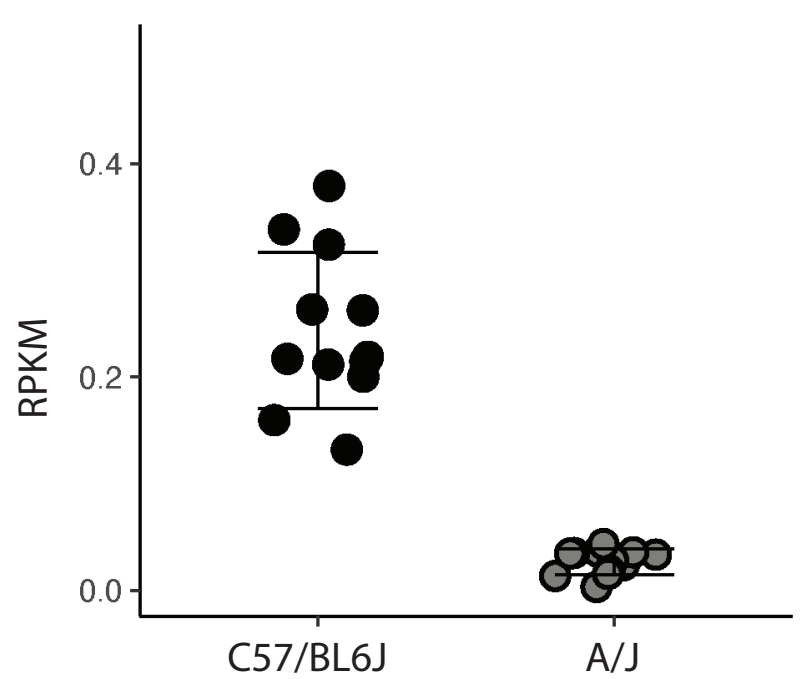

C

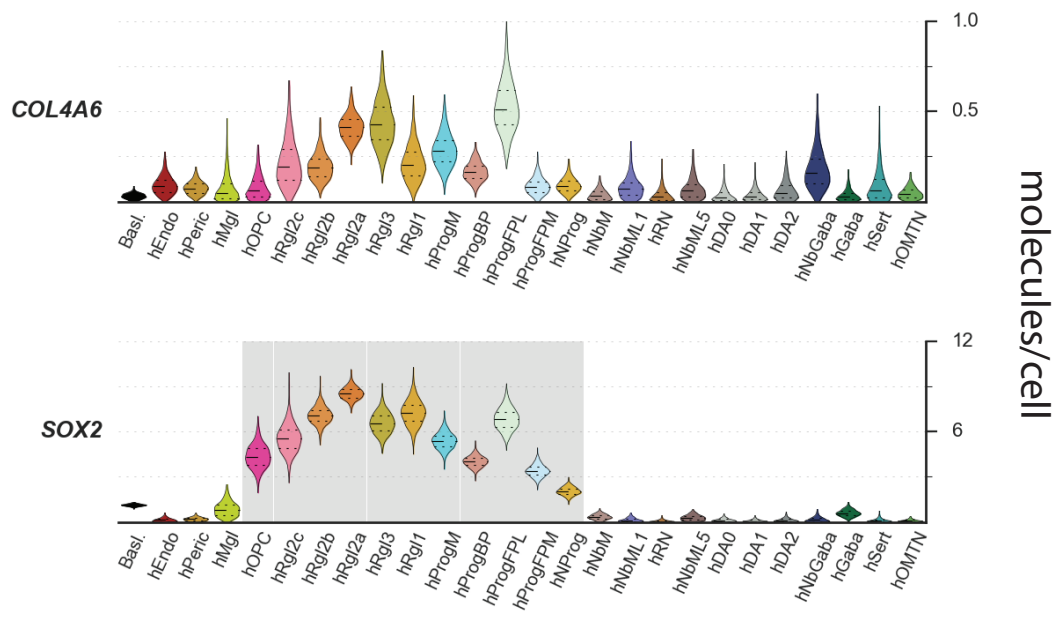


Figure 5

Tyrosine hydroxylase

Striatum

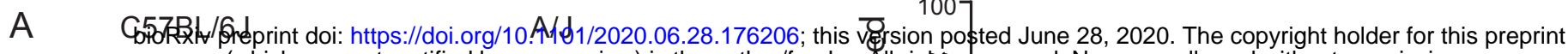
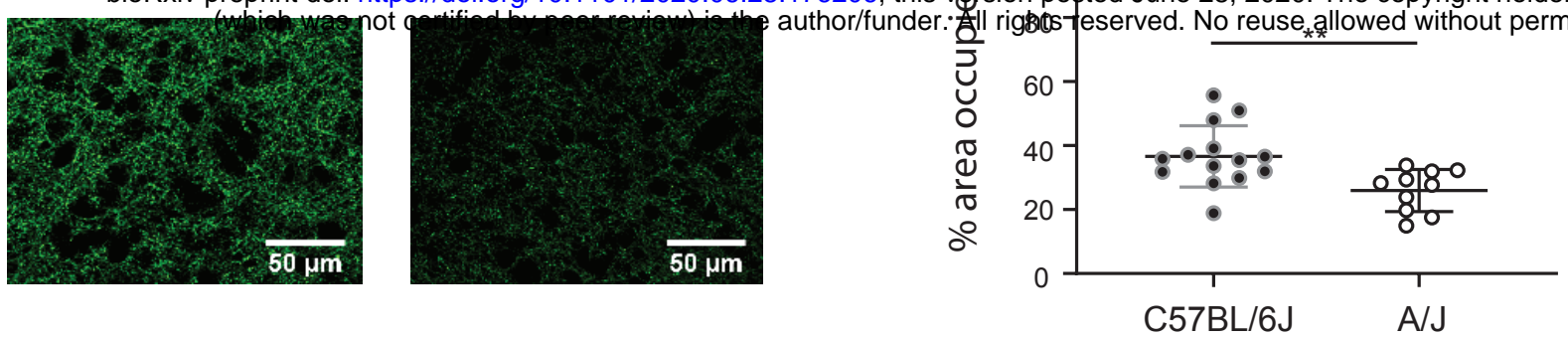

C57BL/6J

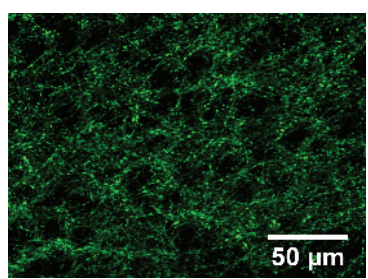

$\mathrm{A} / \mathrm{J}$

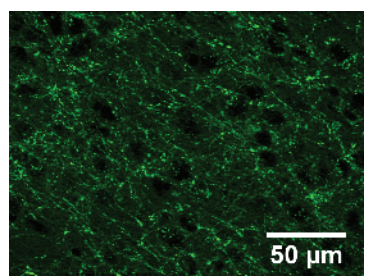

A/J
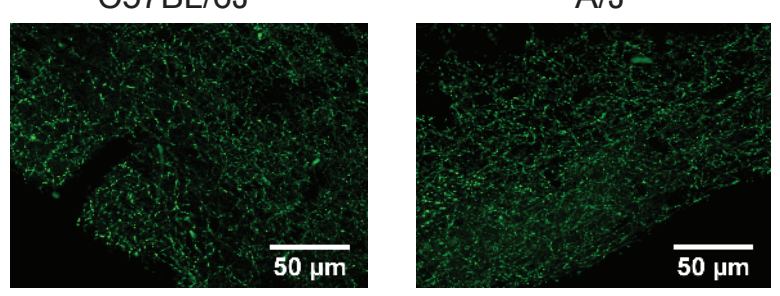

C57BL/6J

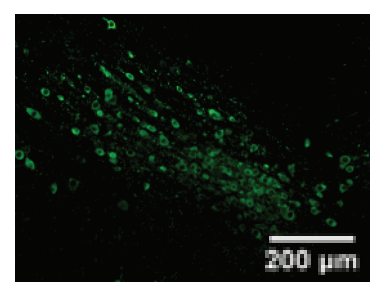

A/J

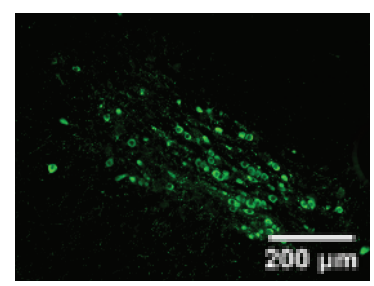

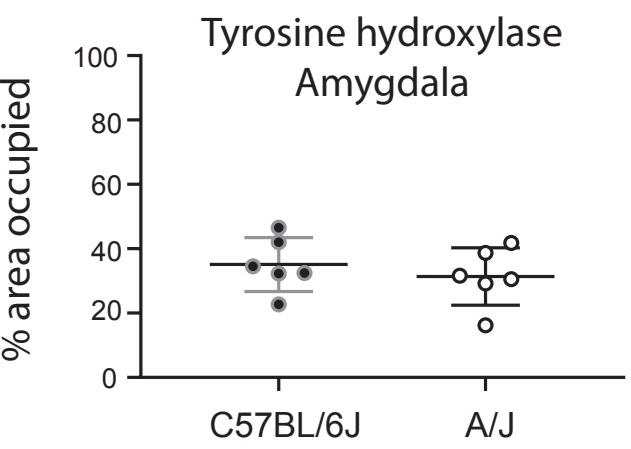
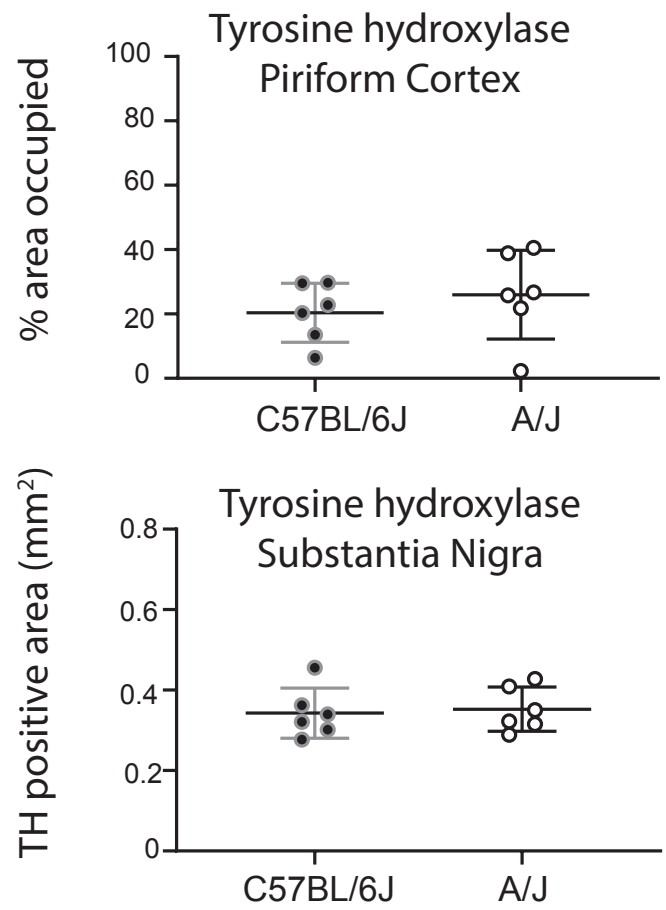